\title{
Just Keep Going - Polyphony. Gentle Activism for Collective Survival
}

\author{
Ryoko Kose \\ RMIT University, Australia \\ s3519533@student.rmit.edu.au
}

\begin{abstract}
This portfolio examines the possibility of my project 'Just Keep Going' series to nurture resilience for those experiencing uncanniness during periods of change and reorganization in the aftermath of extreme experiences.

Experiences in an action-oriented non-verbal polyphony environment that prioritizes the uniqueness of a holistic self while accepting the existence of diverse individuals who are participating in collective survival could foster that resilience.

My practice-led research aims to explore an expanded application of my lkebana practice to my public Spatial Neural-Architectures while exploring a new way of understanding security, survival, and wellbeing. My research informs my art practice that includes the practices arising out of my life experience as an international voluntary evacuee to Australia from the 20I I Fukushima nuclear disaster in Japan.

My portfolio shows the transformation of my artwork and my everyday-life. I investigate how my art-practice could offer a therapeutic experience as well as new cultural framework by examining the methods of Open Dialogue, the Biophilia Hypothesis, Ikebana Philosophy, and Sand-play Therapy. These methods open up new possibilities for a socially-engaged practice that addresses collective traumas in the midst/aftermath of global crisis and the social changes necessary for collective survival.
\end{abstract}

Keywords: survival, ikebana, trauma, polyphony, connectedness

To cite this article:

Kose, R. (2020) Just Keep Going - Polyphony. Gentle Activism for Collective Survival, The Journal of Public Space, 5(4), 323-338, DOI 10.3289I/jps.v5i4.I422

This article has been reviewed by the Editors and accepted for publication in The Journal of Public Space.

This work is licensed under a Creative Commons Attribution - Non Commercial 4.0

International License https://creativecommons.org/licenses/by-nc/4.0/ 


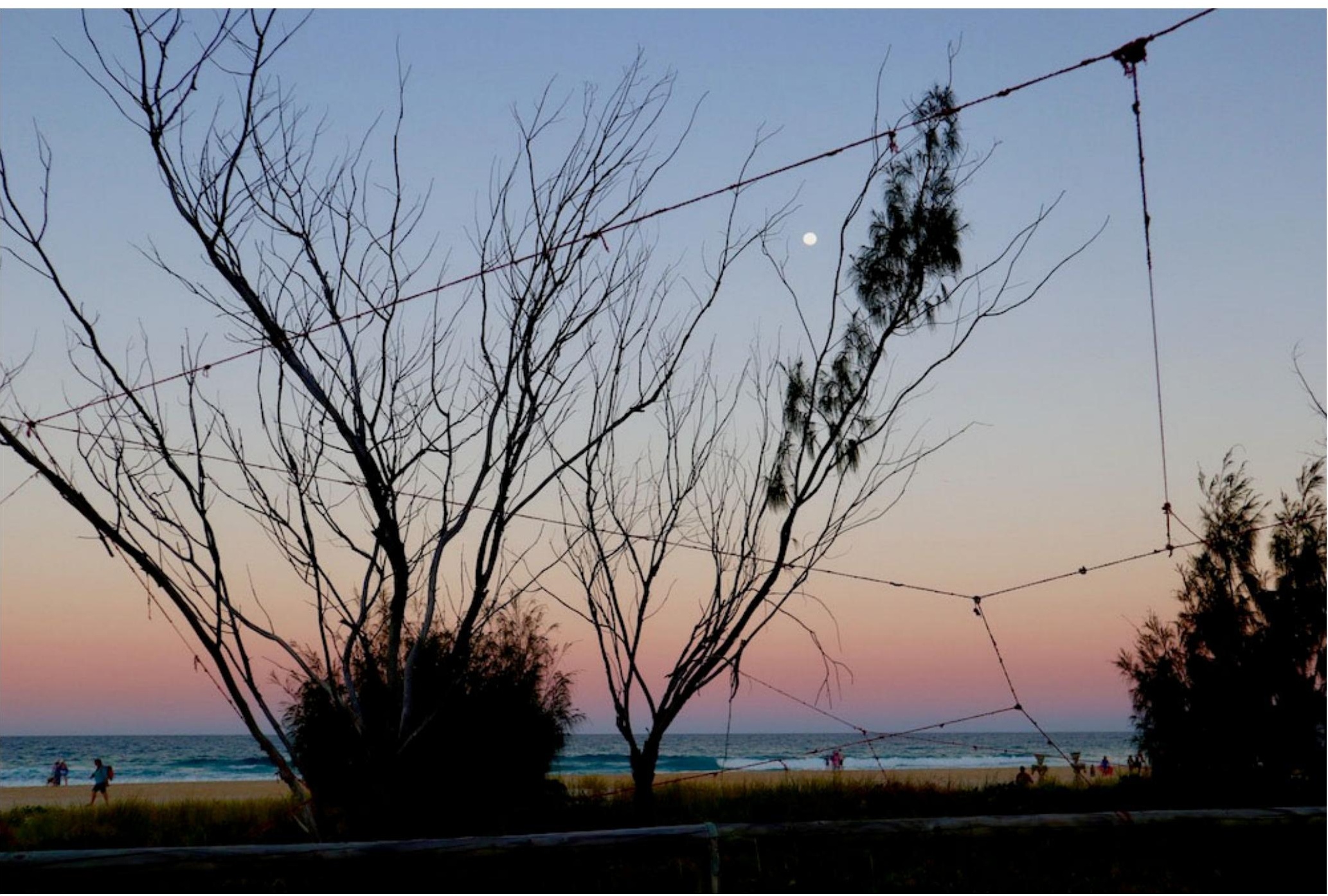

Figure I. Just Keep Going_Departure 2018, Ryoko Kose, Curumbin Beach, Gold Coast for Swell Sculpture Festival, Australia. Installation view. Photograph: Ryoko Kose.

\section{Introduction}

Revising our own narratives is important for wellbeing, especially those who are at turning points in their lives and for those in the aftermath of extreme experiences such as personal, natural, and human-made disasters. When people adapt to new environments, they have no choice but to transform their previously established background identities that were destroyed by the incident/s. Developing new narratives plays a key role in transforming new identities by encouraging reconnection into the continuum of lives followed by problem-solving and then integrating the beginning of new personal and social changes. This process usually needs a 'safe' environment and empathetic encouragement because facing new realities, confronting new customs, and finding one's own voice often is the cause of tension, fear, and trauma. To revise different individual narratives, it is also important to reinforce individual uniqueness by accepting the uniqueness of others. 
However, in periods of extreme uncertainty, access to 'safe' environments in which to explore the personal search for physical and emotional survival is very limited. Extreme incidents often force examination and revision of many kinds of daily life frameworks developed long before the incident/s happened. Physical survival requires changes in ways of thinking that lead to lifestyle changes. In addition, it is necessary to interact with groups of individuals with various values, as well as varied physical and social needs.

Difference is revealed dramatically. This can lead to huge emotional affects arising out of all of the conditions described above. The more dramatic the adaptation, the stronger the confusion and grief experienced as consequences of the event/s.

In this time of confusion and grief, there is a need for alternative ways of understanding the situation that is alternative and additional to language-based reflection.

In my experience, this is because emotional trauma can be exacerbated by confusing relations arising from language-based reflection making it very difficult to examine oneself honestly. Language-based reflection is likely to invite short-cuts to emotional understanding in order to rationalize what happened and what must change. This places language-based reflection before full inspection of emotions. From my personal experience, in a disaster and extreme uncertainty, emotional understanding must come before intellectual language-based understanding.

Drawing on my experience, I have found that there is a sequence to addressing and healing traumas. In the first stage, there is no need to understand one's emotions because the trauma is first trapped in the body. The entrapment is at the level of the unconscious. Seeking to uncover trauma with language-based reflection can block some things in the unconscious that need to be revealed as they rise to consciousness from the unconscious.

My project begins with a search for personal emotional understanding through art processes. In this portfolio, I examine the therapeutic aspects of my project in order to nurture my personal resilience. I describe my project first, followed by the background of the projects, and then I present the transformation of my artwork and private life through revelations in my art processes.

\section{My project and background}

In my Master of Arts (Art in Public Space) research at RMIT, my interests combined with my lived experience of the Fukushima nuclear disaster and my domestic and international 'voluntary' evacuations. I have lived in a margin between political systems, with on-going daily-life survival in uncertainty in the aftermath of that incident for about nine years.

I lived in Tokyo when the disaster occurred and I had several big radiation exposures there in the first year of the accident. The accident is currently ongoing nine years after it began because the solution to settle the unstable reactors down has not been found.

Radiation has been distributed all over the world, especially in the areas near Fukushima such as Tokyo where the fall out of radioactive materials is observed every month since the accident. Soon after the accident, the radiation exposure started affecting my health. Then I found that my apartment in Tokyo and all the items inside were too contaminated to live in and with, which made me decide to become a 'voluntary evacuee.' The disaster has affected not only my physical life but also my internal life. My identity and understanding of the external world have become confused by my domestic 
and international evacuation, which dramatically changed my way of living and my understanding of security and survival.

Throughout my nine-year evacuation, I have tried to untangle the enormous complexity of the issues I have experienced. My project arose out of the complexity of the nuclear accident and its aftermath, caused by the character of radiation; invisible, intangible, difficult to measure and quantify as energy. In addition, its profound effects on all human and living life in the ecological system are yet to be fully examined in evidence-based science.

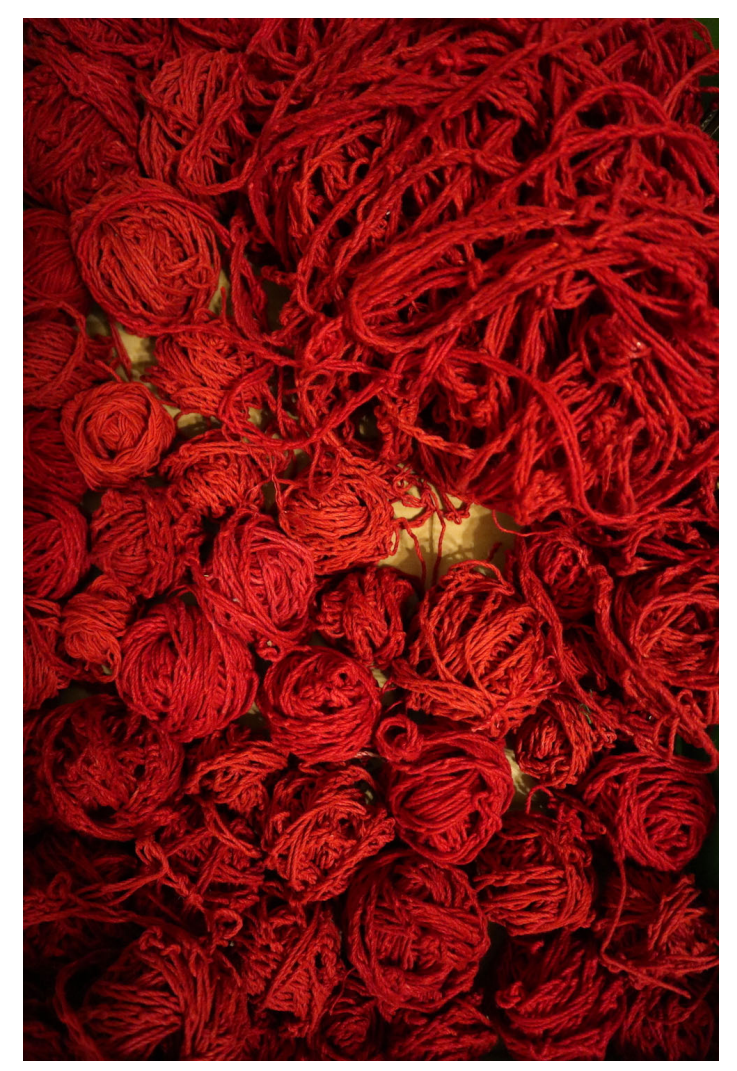

Figure 2. Just Keep Going, 2017, Ryoko Kose. Detail of the material.

Photograph: Ryoko Kose.

After Fukushima, my art practice proved to be a coping mechanism for my everyday life adversity, as an 'invisible' environmental refugee without any access to political and social supports. Transcultural 'voluntary' evacuation and being a mother have forced me to adapt to whatever is available to me.

My art practice has enabled me to process grief by revealing what happened to me. It also has encouraged me to revise my narrative constantly. I adapt and then share that with an audience through my art practice, primarily in public. venues This has resulted in transforming my practice toward a gentle activism for those living in uncertainty for both their daily-life and life-long survival.

My art practice has helped me manifest through materials my internalized experience and my understanding of the external concepts and issues relevant to my practice. The installations in my master's research aimed to represent life in flux. These works turned 
out to be precise re/presentations of my physical and mental situation when I created them.

In my practice, I have found it remarkably interesting that the artwork changes in advance of my life. I can say that my way of thinking, or way of committing to society and/or myself, manifests changes arising from the art practice. I find that those changes and subsequent realizations then give me a chance to change my actions and my conceptual framework and which, in turn, change my style of life. Through my practice from a Master's to a PhD, my artwork 'told' me that my interests have been transformed from individual survival to collective survival.

\section{Transformation of my work and life}

The first work of the 'Just Keep Going' series was created in 2017, Three years after I moved to Australia. In that year I enrolled into Master of Art- Art in Public Space in RMIT on a two-year visa. Until then, I was physically busy with parenting my three young children and had no time to reflect on my situation and myself.

I created a test work in public as an intervention for self-reflection. Moving hands as an exploration of an artwork forced me to open something in my body. This first work revealed my trauma from the Fukushima nuclear accident and my evacuation. I also recognized that this work was created by applying Ikebana Philosophy, an element of which aims for self-reflection in order to connect the inner self to the outside world.

Figure 3. Just Keep Going_Look up in the Sky, 2017, Ryoko Kose, Testing Ground, Melbourne, Australia. Installation view. Photograph: Ryoko Kose.

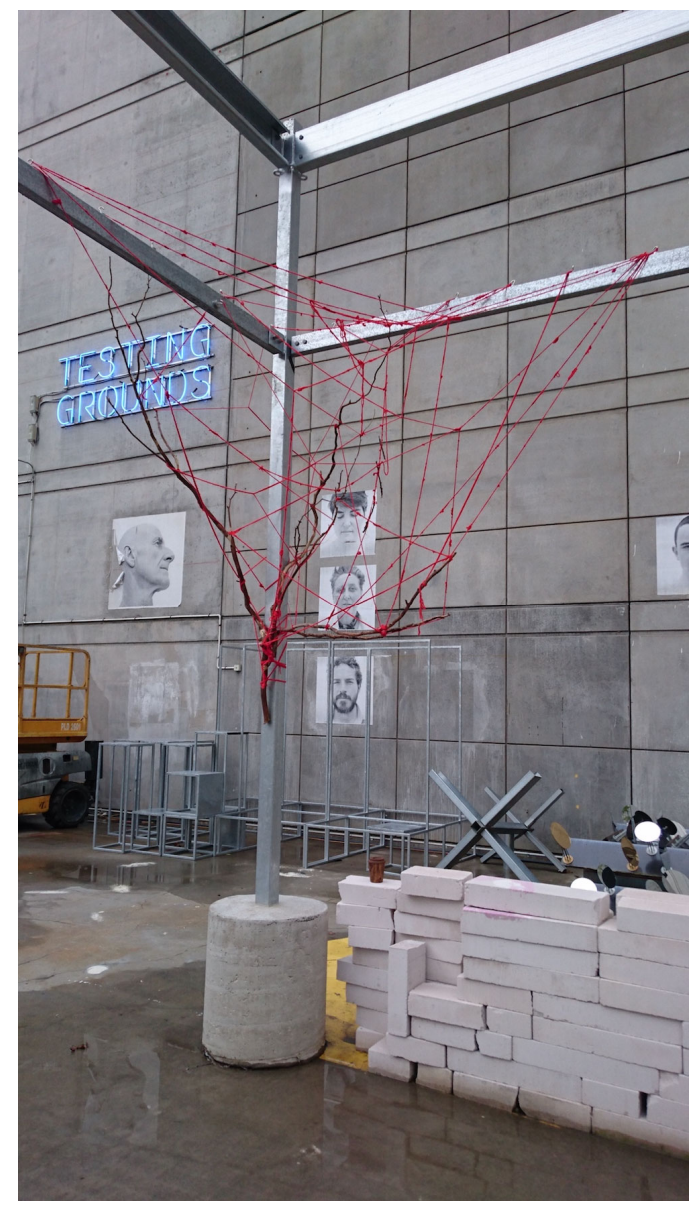


'Just Keep Going' was originally developed as an installation to create a safe environment to encourage self-reflection. This work was inspired by two elements of Ikebana practice. The first was the equilibrium between forces of all living creatures in the universe, inanimate objects and artificial things in a specific time and space. Nothing is definitive, everything is in flux and connected. Second, my activation of spaces with simple interventions is similar to ikebana practice by using lines and negative-space to create a composition. Characterized by extreme minimalism and discipline, ikebana requires that the practitioner intensely study the specimen to ascertain how to best emphasize its form. Furthermore, Ikebana maximizes the potential not only of flowers and vases but also of the place where the artwork is installed. I believe lkebana is a sitespecific practice that aims to achieve harmony with the environment. Simple but strong composition has the power to make space a place without assertiveness.

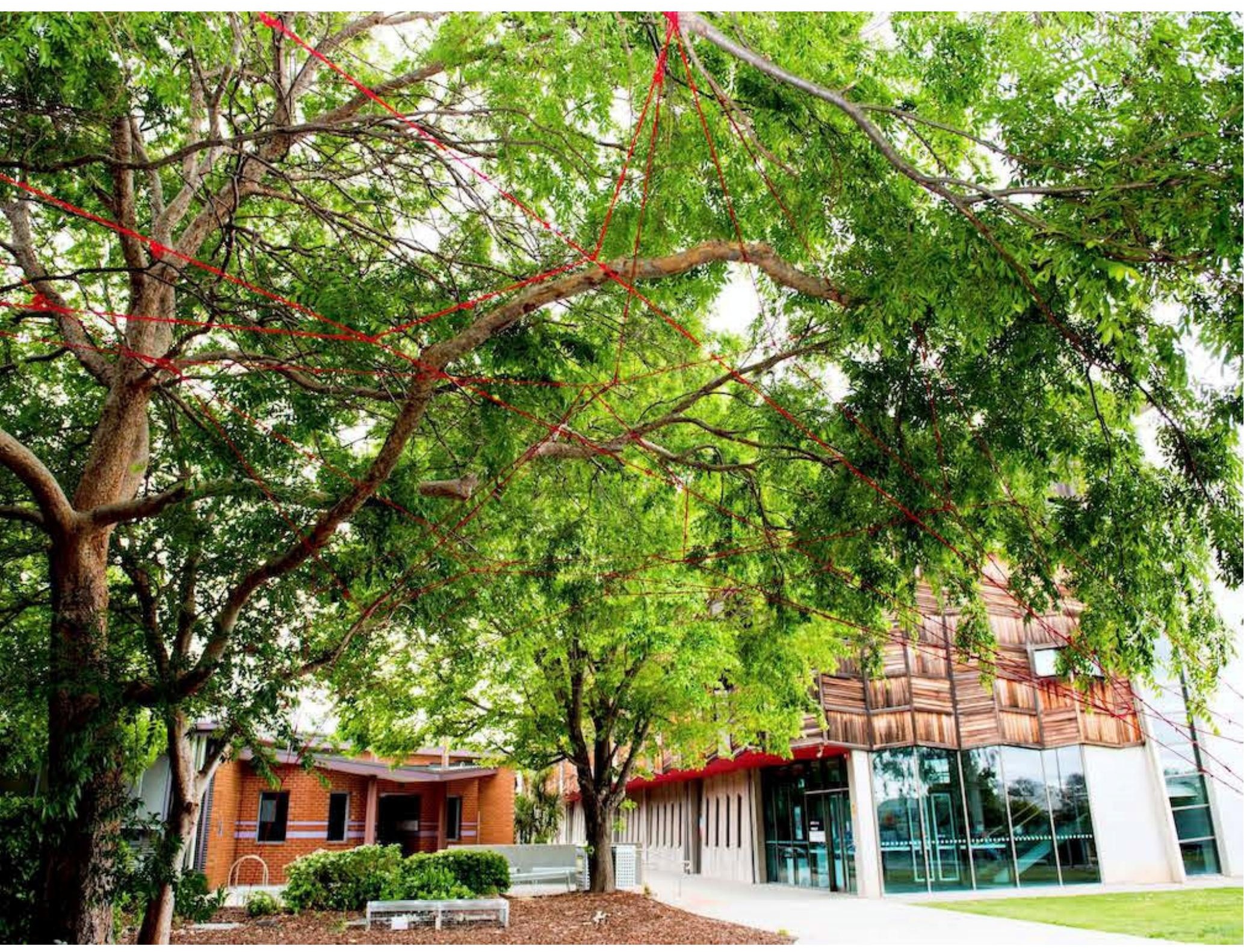

Figure 4. Just Keep Going_Encouragement, 2017, Ryoko Kose, RMIT Brunswick Campus for a public art event 'Artland', Brunswick, Australia. Installation view. Photograph: Olivia Blackburn.

328 | The Journal of Public Space, 5(4), 2020 | ISSN 2206-9658

City Space Architecture / UN-Habitat 
My artwork 'Just Keep Going' is a 3D line-drawing installation/performance series with projections. Crocheted hemp yarn is directly applied to various structures in a range of sites across Australia. The yarns are then re-used in consecutive sites, bringing all the experiences and memories from one site to another. I engage playfully with each site I work in using neither nails nor hooks for attachment. The composition of the woven yarns represents lives that exist in rhizomatic ways without structures or hierarchy. The composition moves beyond language and culture to build connectedness. The yarn has no beginning and no end. (Deleuze \& Guattari 1987 cited in Colebrook, C., 2003) The work transforms depending on the point of the view of the person who comes to it implying that we all are living different lives, each with different values developed by different cultural, political, religious, racial, social, generational and gender backgrounds. Audiences, space, materials, textural elements, and the life that inhabits each site coalesces in a process of constant 'becoming.' Identities are transformed by mutual encounters. These aspects are folded into a specific time and place

Since then, my creations have led me to interesting and useful reflections. For example, the bright red colour of the yarn is used in our culture for the celebration of new-born babies, coming-age, long-life and so on. It represents 'celebration of life' and hope to just keep going. Installation views at night gave me another reflection. All the colours of the work including those in Nature are banished, which reminded me of the negativity in my body. For example, fear of death and sickness caused by radiation exposure, or that in the darkness, I was ignorant of radiation contamination when I was exposed. Installing yarn in public for a certain amount of time shifted my practice to the concept of process as an artwork. I installed artwork as a residency, in the gallery and public areas around a shopping mall, always accompanied by my 2-year-old, 3-year-old and 5year-old children. We spent the whole time in the Gallery. Weaving together, going for a walk, exploring to the mall, painting, embroidery and so on. This changed my concept of artwork from something created on a special occasion to something that emerges from everyday life.

At this stage, I was also challenged to represent my experience of disaster and struggle of displacement to the public. I found, however, that those works created a boundary between artwork/myself and the viewers. Viewers felt no relation to them in their daily lives. Yet, the uranium in the Fukushima nuclear reactor was exported by Australia, and in Australia, there are those who are suffering radiation sickness due to that mining. My experience was completely objectified and understood as a representation of a historical disaster.

I learned ikebana practice from my grandmother, who practiced with materials from her natural surroundings. In my practice, the yarn travels from site to site bringing all the memories and experiences of all the places where it had existed previously. This is the metaphor of life. Once we move into a new place, we start to explore, to find, and build connections to others. We sometimes take wrong directions, then stop or return, sometimes we come to a dead-end, sometimes we go too far away then come back to our life.

Through time and space, the yarn transformed after being uninstalled from various sites by being untied and untangled carefully. The choice of material instead of flowers derives from my fear of contaminated land. The displacement of yarn from site to site represents my unsettledness due to my visa situation. 


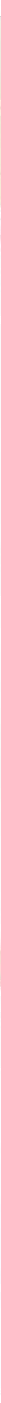

Figure 5. Just Keep Going_Sanctuary, 2018, Ryoko Kose, The Artists Guild in The Dockland District, Dockland, Australia, for the International Womens' Day, Documentation image. Photograph: Ryoko Kose. 

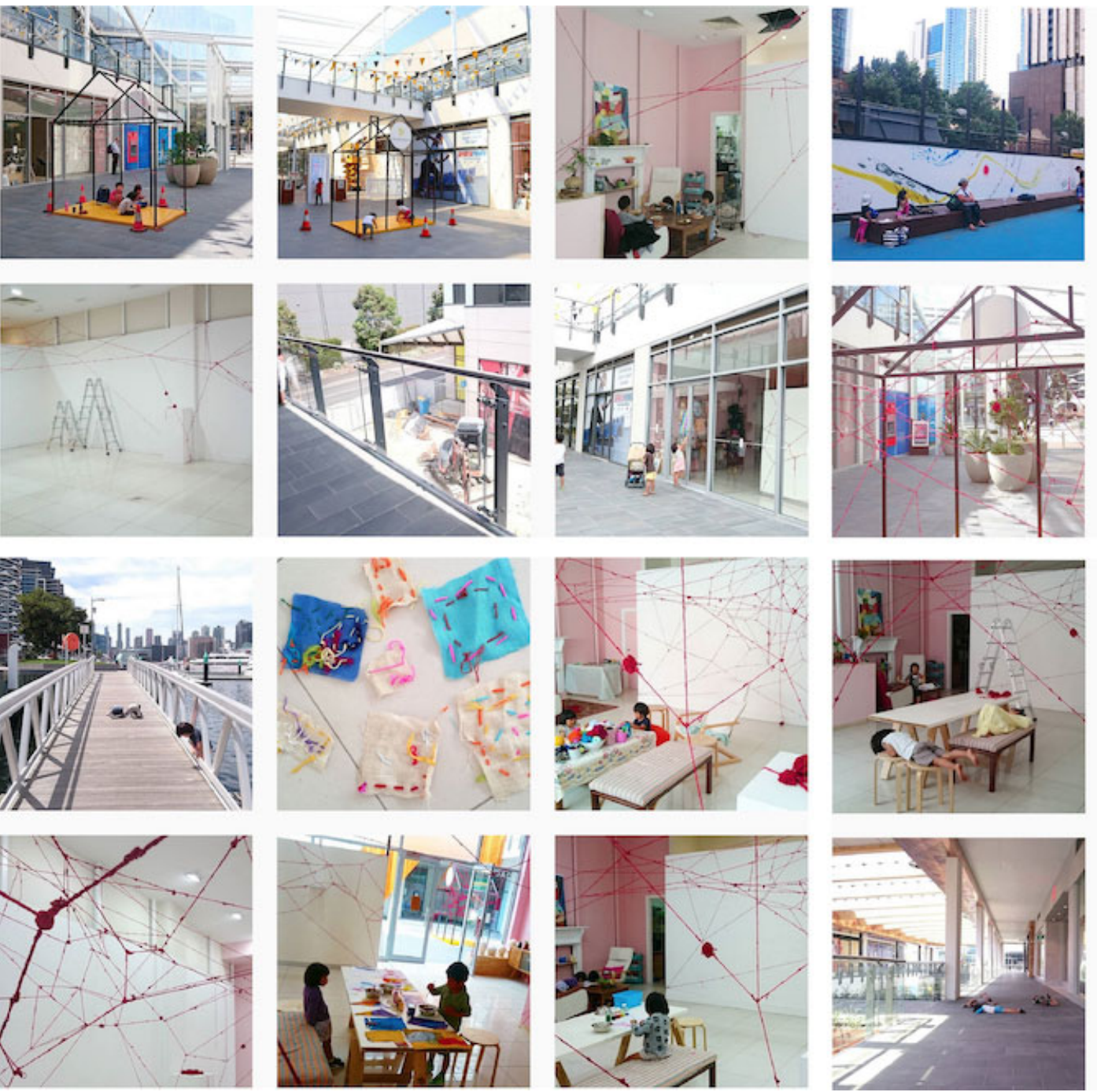
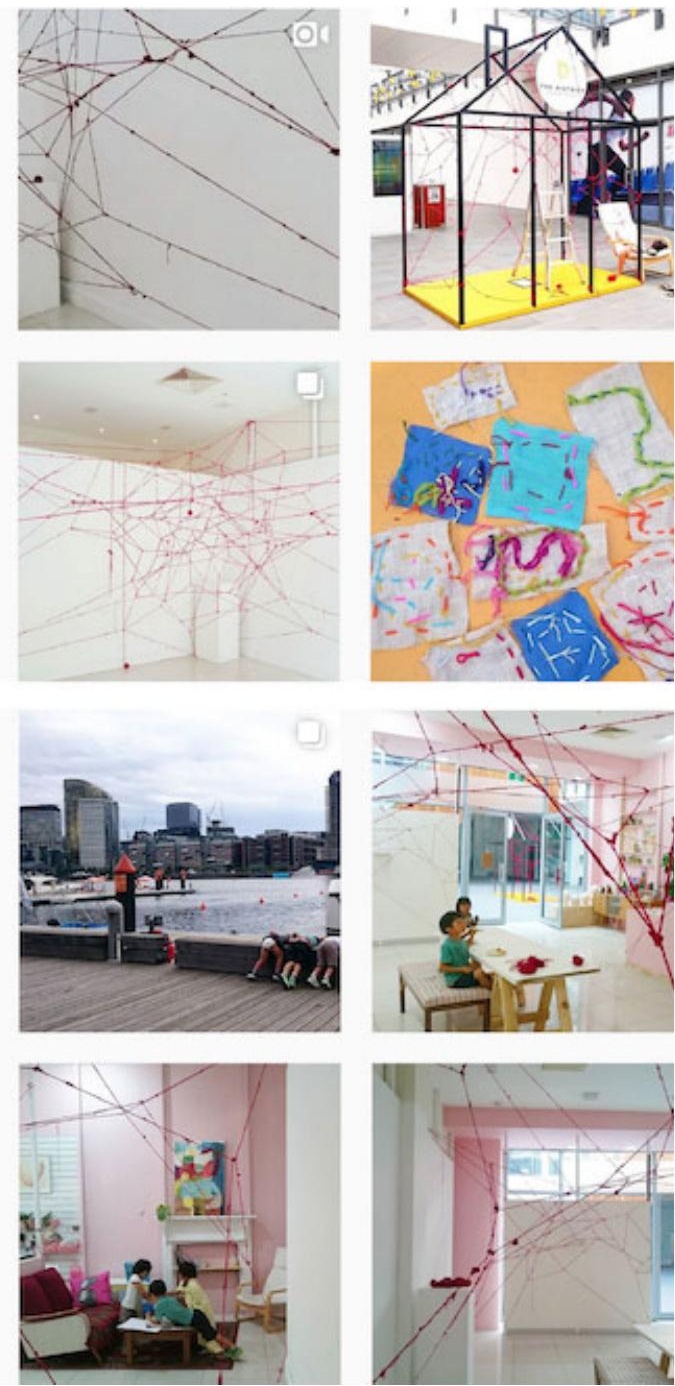

Figure 6. Just Keep Going_Sanctuary, 2018, Ryoko Kose, The Artists Guild in The Dockland District, Dockland, Australia, for the International Womens' Day, Documentation image.

Photograph: Ryoko Kose. 

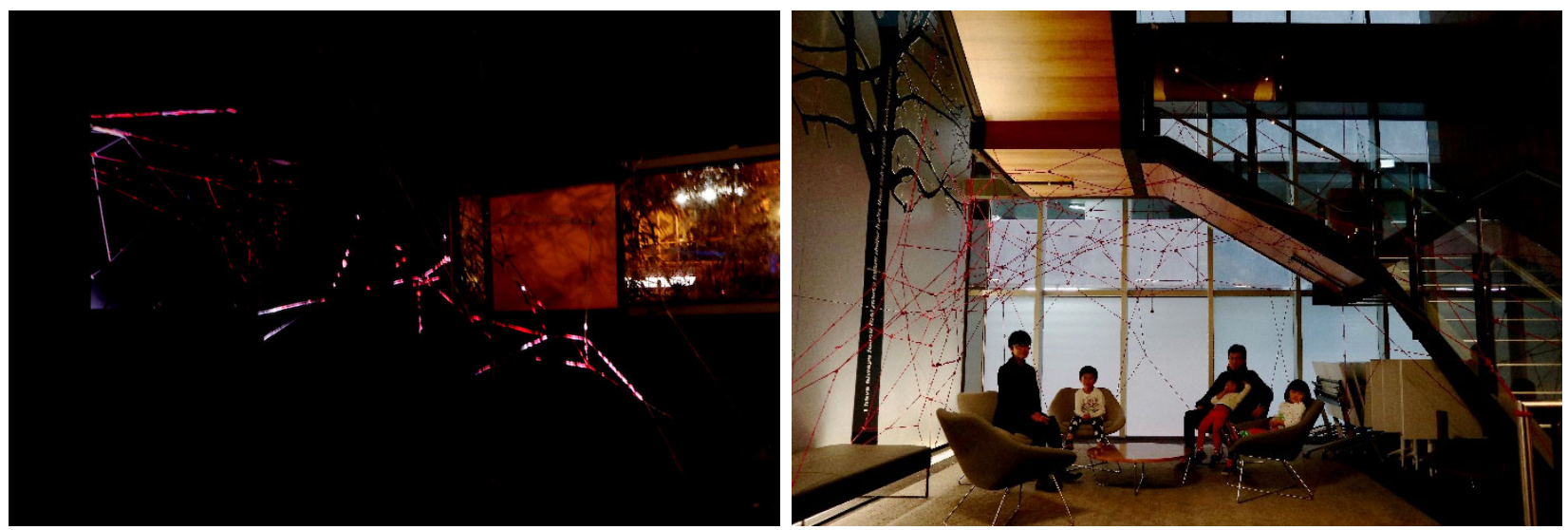

Figure 7 (left). Just Keep Going_Disaster, 2018, Ryoko Kose, Testing Ground, Melbourne, Australia. Installation view. Photograph: Ryoko Kose.

Figure 8 (right). Just Keep Going_Displacement 2018, Ryoko Kose, Monash Law Chambers, Melbourne, Australia for the public event by Monash Gender, Security and Peace 'Displacements : From Everyday Experience to Global Policy', Documentation image. Photograph: Ryoko Kose.

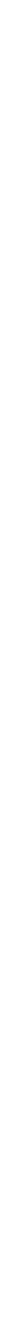

Figure 9. Just Keep Going_Layers of Life 2018, Zeljko Radic and Ryoko Kose, Post Industrial Design for West Projection Festival, West Footsclay, Melbourne, Australia. Installation view.

Photograph: Ryoko Kose.

332 | The Journal of Public Space, 5(4), 2020 | ISSN 2206-9658

City Space Architecture / UN-Habitat 
So, next, I tried to represent the constraints between people with positive meanings. This became a unique celebration in order to accept the concept that we are living together in this time and place by affecting each other.

In the next site, while the yarn was installed by the sea, it became partly covered with salt from ocean, the sand from the beach, and a lot of fresh spider webs from the ground. This means all the elements in the site such as the yarn, the people, the trees, showers, the fence, the grasses, the sea, the sand, the sky, the sun, the moon, the stars, the wind, the life that inhabits the site are part of the artwork and create a little universe.

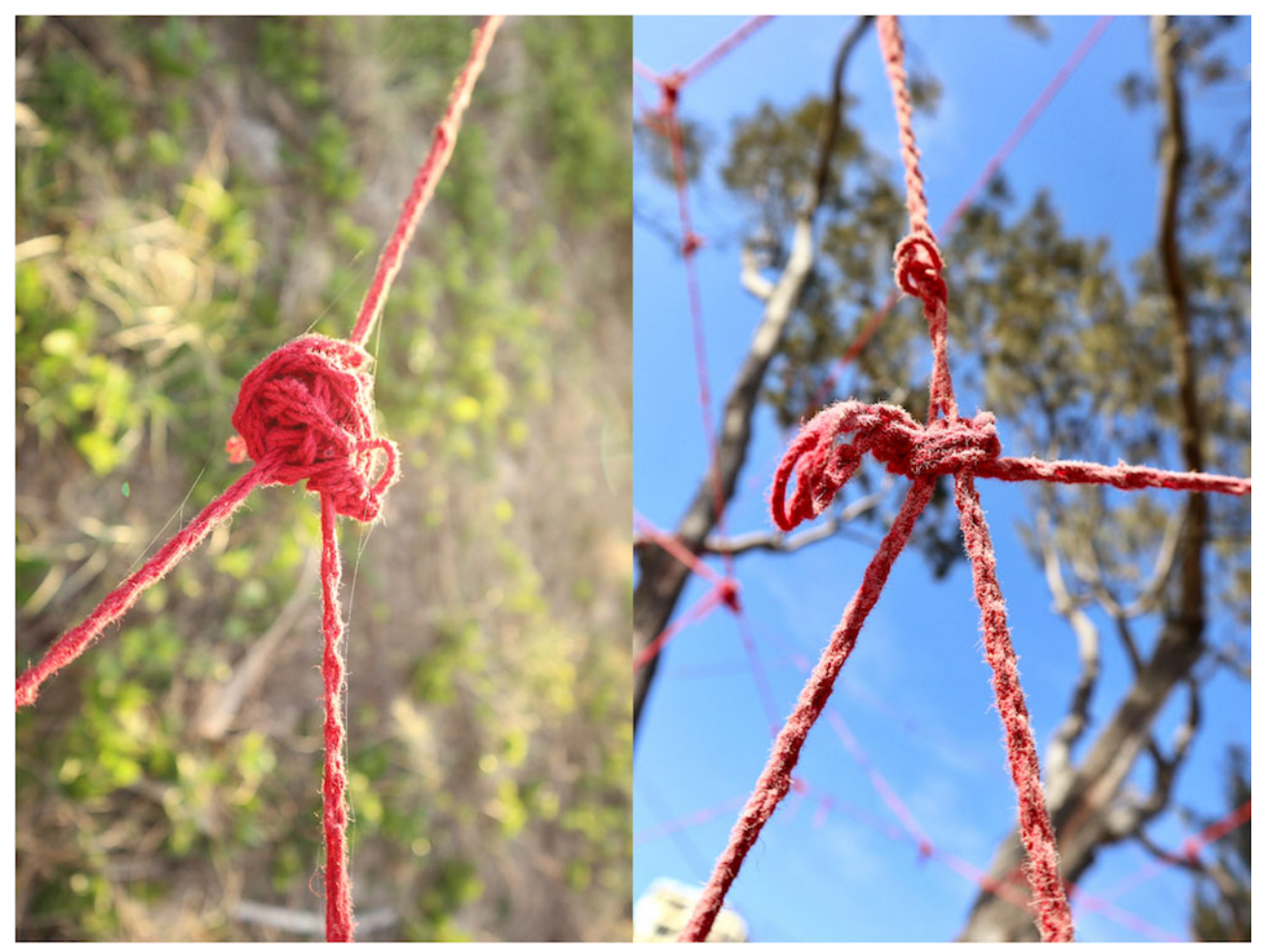

Figure 10. Just Keep Going_Departure, 2018, Ryoko Kose, Curumbin Beach in Gold Coast for Swell Sculpture Festival, Australia. Detail. Photograph: Ryoko Kose.

Then a trickster visited me. In uninstalling the yarn, I had to cut all the yarn applied on the structures on the site so I could quickly get on the flight back home. I did that with a bit of hesitation but enabled me to refresh myself dramatically. I thought the cut yarn on the ground looked like it was bleeding and detoxifying.

Three months after this work, I experienced a very strange drama just after I finished my final presentation for Master's study. I accidentally discarded all the yarn I had grown up with and brought with me instead of a collection of my children's old clothes. Another trickster arrived. I was very shocked and felt great loss at first. However, gradually I came to feel that accident seemed to remove a bit of burden from my shoulders. After that, I received an offer for PhD study in RMIT, followed by another temporary visa that secures my stay in Australia for a maximum of eight years. 


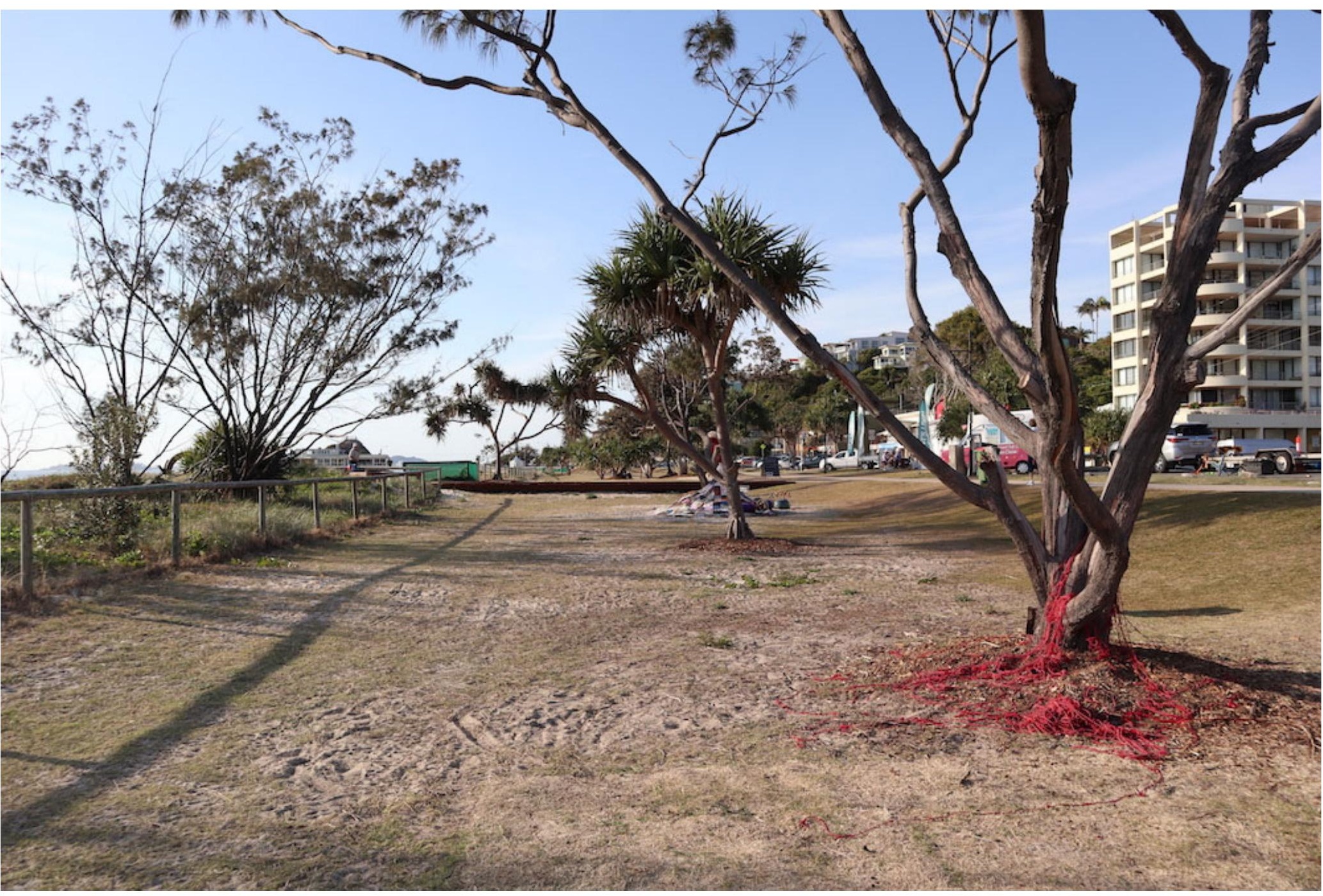

Figure II. Just Keep Going_ Departure, 2018, Ryoko Kose, Curumbin Beach in Gold Coast for Swell Sculpture Festival, Australia. Installation view. Photograph: Ryoko Kose

At the start of my PhD I developed a combination of installation and performative works that involved five representative actions: knitting to reinforce, weaving to connect, cutting to destroy, sleeping to recover, and untangling to revise something previously felt or known. These works represented me trapped in my internalized thoughts and situations enclosed in my chrysalis. After this, I started to explore collective survival in order that I could survive.

I developed a participatory collaboration with the visitors to a public sculpture festival in the Gold Coast'. The participants were invited by written instructions on site to make something representing their unique connectedness to others. This time, I just stayed and worked by myself in the site and facilitated participants as sometimes required. The participants creating their own pieces were very calm and inspired by each other. The developed installation could be described as being 'a worship of the uniqueness of life.'

\section{Note}

'This project was developed as a commissioned work and not included in Ryoko Kose's PhD research. 


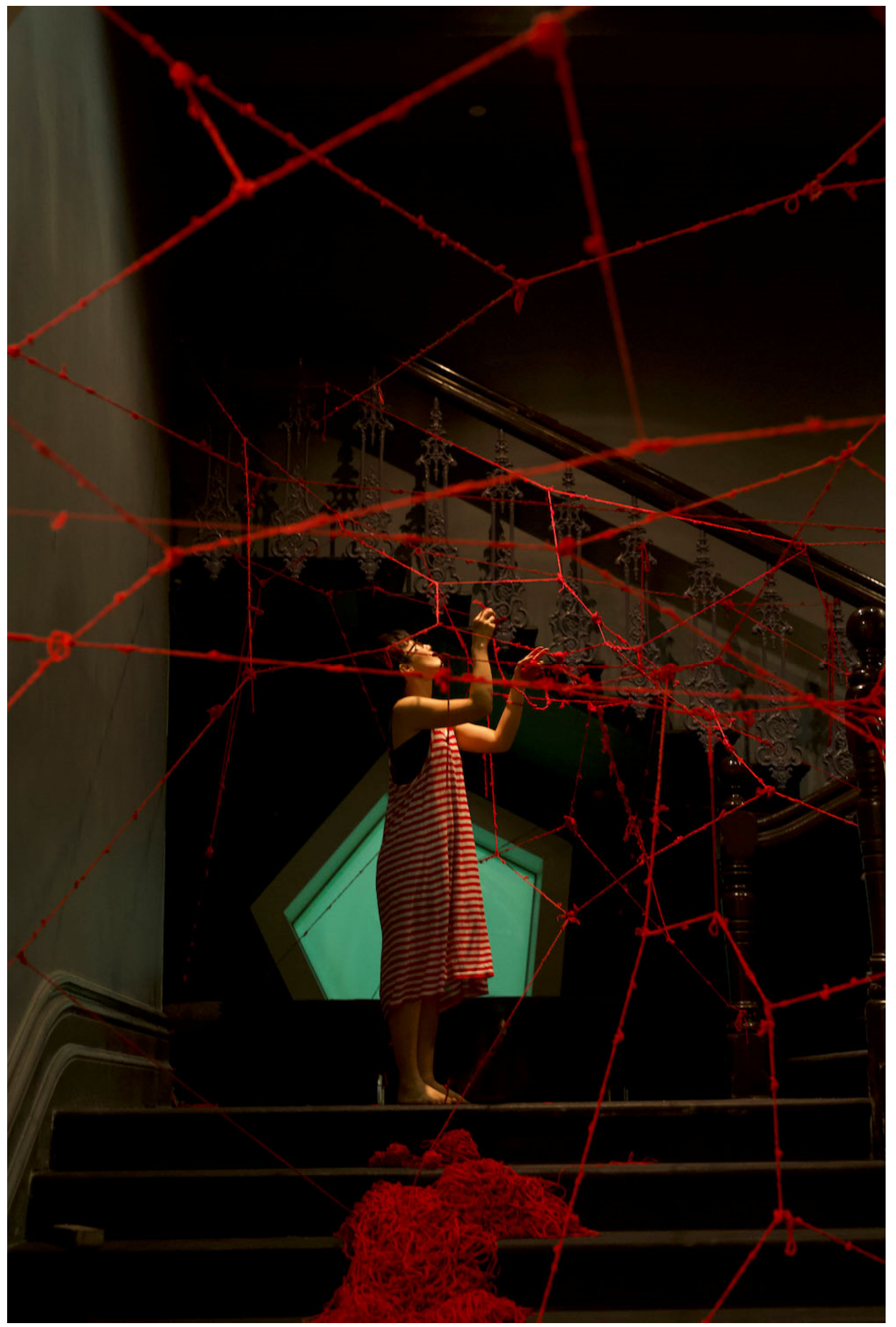

Figure 12. Just Keep Going_It Is Like Something, 2019, Ryoko Kose, RMIT Gallery for 'Bruised: Art Action and Ecology in Asia' a part of ART+CLIMATE=CHANGE 2019.

Documentation image. Photograph: Atong Atem 


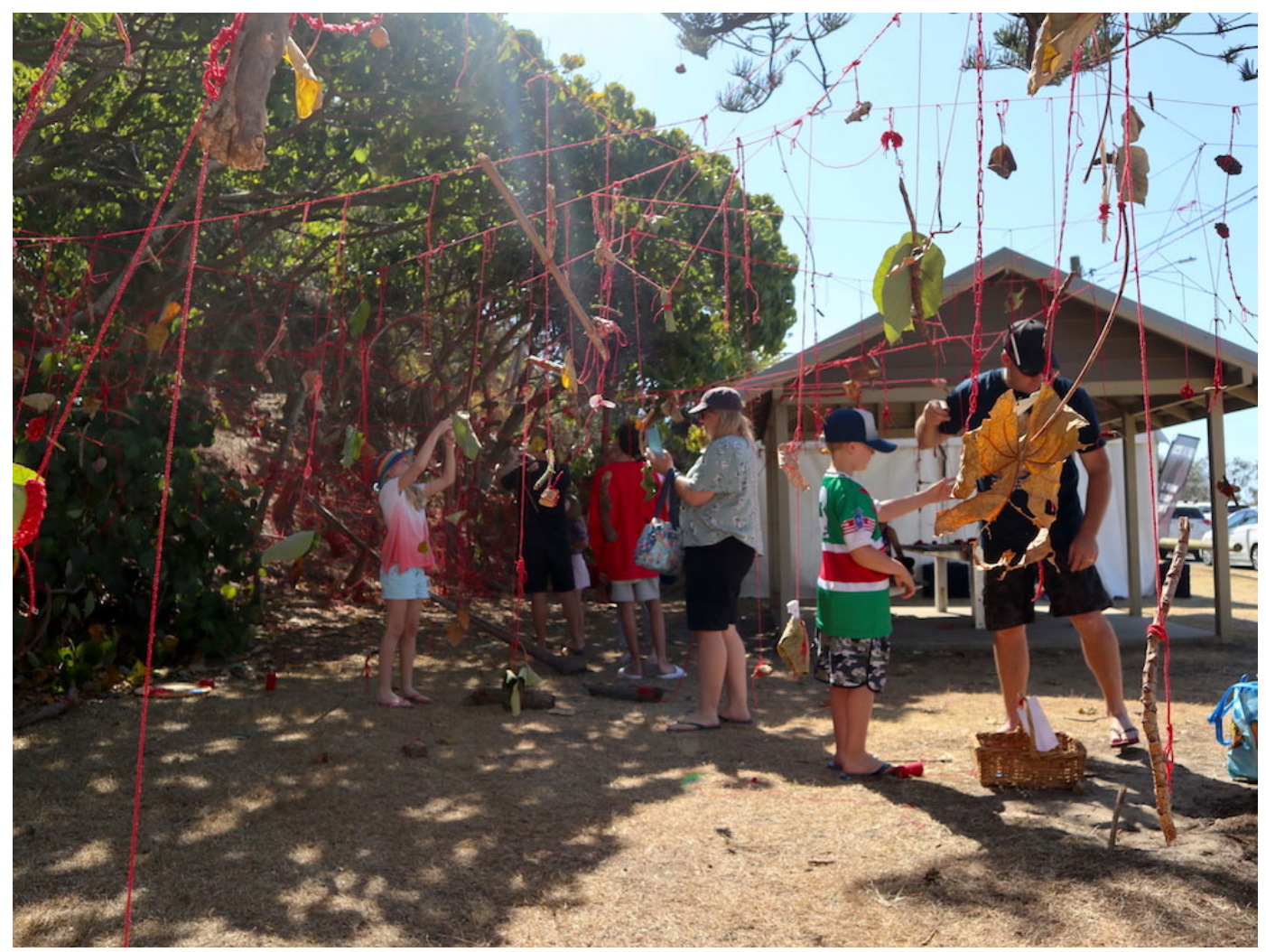

Figure 13. Just Keep Going_Elements, 2019, Ryoko Kose, Curumbin Beach in Gold Coast for Swell Sculpture Festival, Australia. Documentation image. Photograph: Ryoko Kose.

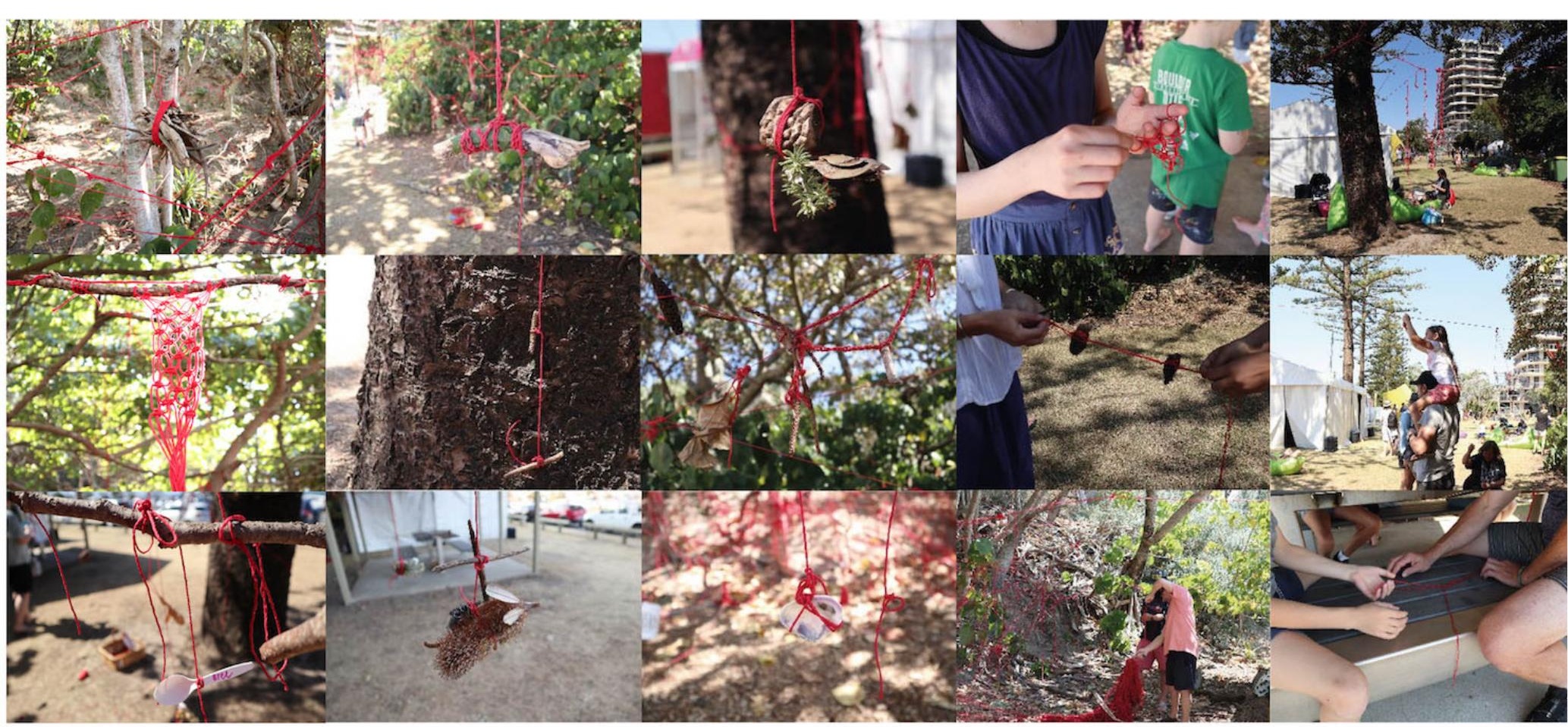

Figure 14. Just Keep Going_Elements, 2019, Ryoko Kose, Curumbin Beach in Gold Coast for Swell Sculpture Festival, Australia. Detail of the art pieces. Photograph: Ryoko Kose.

336 | The Journal of Public Space, 5(4), 2020 | ISSN 2206-9658

City Space Architecture / UN-Habitat 


\section{Therapeutic aspect of my work and Conclusion}

In this portfolio I have explored the motivations, projects, personal transformations, and therapeutic elements of my practice. I have demonstrated how aspects of Ikebana practice can nurture resilience. In my practice, I found four critical factors that identify social-ecological systems, resilience during periods of change, and reorganization: (I) learning to live with change and uncertainty; (2) nurturing biological and cultural diversity; (3) combining different types of knowledge for learning; and (4) creating the opportunity for self-organization (Folkeet al. 2002).

Through the projects, I enjoyed 'polyphonic' (Anderson \& Goolishian 1988, cited in Seikkula, J. \& Olson, M.E. 2003) relationships with the elements of sites. The animate and inanimate objects become multifaceted aspects of myself. This makes me feel like I am having a dialogue with them in my whole body. All my feeling, thoughts, and reflections are affirmed and celebrated by the environment. This revelation led me to prioritize the uniqueness of a holistic self and to accept the diversity of individual ways of adapting to uncertain situations. These notions come from Ikebana Philosophy developed from Japanese indigenous concepts. I observe similar adaptations in people with non-Japanese backgrounds that could be explained with E.O. Wilson's Biophilia Hypothesis. Through art practice, we have the potential to access the three Open Dialogue principles: tolerance of uncertainty, dialogism and "polyphony in social network" (Seikliula et al., 200I) when we try to connect to Nature and natural environments.

Open Dialogue focuses on process itself, not achievement. Similarly, indigenous Japanese perspectives on therapy tend to emphasize finding internal peace through process and adapting to one's circumstances in productive ways (Enns and Kasai, 2003) Sandplay Therapy, known as Hakoniwa Therapy in Japan, has similar effects to Ikebana practice. It focuses on artistic, holistic, non-rational, spiritual, and nonverbal aspects of knowing (Kawai, 1996). Both allow us to act out internal reality, experience transcendence through experimentation, and prepare ourselves for productive action that arises out of acceptance.

My action-oriented practice promotes revision, transformation, and adaptation of personal narratives. By experiencing and examining connectedness to others, this practice can accommodate diverse individual resilience in post-crisis contexts that can in turn lead to and foster resilience at broader social-ecological scales. Nurturing this cultural-framework is critical in order to face issues in front of us, make decisions, and take actions for collective survival. This chain of processes opens up new possibilities for a socially-engaged practice that confronts collective trauma in the midst/aftermath of global crisis and encourages social change for collective survival. 
Just Keep Going - Polyphony

\section{References}

Colebrook, C. (2003), Understanding Deleuze, Taylor \& Francis Group, 2003. P29-30

Enns, C \& Kasai, M. (2003) 'Hakoniwa: Japanese Sandplay Therapy', The Counseling Psychologist, Vol.3I, January 2003, P.I09

Folke, C., Carpenter, S., Elmqvist, T., Gunderson, L., Holling, C. S., \& Walker, B., (2002)

'Resilience and sustainable development: Building adaptive capacity in a world of transformation', P. 34, The Environmental Advisory Council to the Swedish Government. Johannesburg, South Africa.

Kawai, H. (1996) Buddism and the art of psychotherapy, College Station: Texas A\&M University Press, U.S.

Seikkula, J., Alkare, B., \& Aaltonrn, J. (200I) 'Open dialogue in psychosis I: An introduction and case illustration', Journal of Constructivist Psychology, vol. I4, 247-266.

Seikkula, J. \& Olson, M.E. (2003) "The Open Dialogue approach to acute psychosis: Its poetics and micropolitics", Family process, vol. 42, no. 3, pp. 403-18. 